\title{
Formoterol for the Treatment of Chronic Obstructive Pulmonary Disease
}

This article was published in the following Dove Press journal:

International Journal of Chronic Obstructive Pulmonary Disease

\section{Donald P Tashkin}

Department of Medicine, David Geffen School of Medicine at UCLA, Los Angeles, CA, USA
Correspondence: Donald P Tashkin David Geffen School of Medicine at UCLA, 10388 Le Conte Avenue, Los Angeles, CA 90095, USA

Tel + I 3108253163

$\mathrm{Fax}+$ I 3102065088

Email dtashkin@mednet.ucla.edu

\begin{abstract}
Bronchodilators, including long-acting $\beta_{2}$-agonists and long-acting muscarinic antagonists, are the mainstay for treatment of patients with chronic obstructive pulmonary disease (COPD) to prevent exacerbations or reduce symptoms. Formoterol is a highly selective and potent $\beta_{2}$-agonist that relaxes airway smooth muscle to significantly improve lung function. Inhaled formoterol works within 5 minutes of administration and provides improvements in spirometry measurements over 12 hours. The lipophilicity of formoterol allows it to form a depot within the smooth muscle to provide a prolonged duration of action. Following therapeutic doses, plasma concentrations are very low or undetectable. Determination of the pharmacokinetics of formoterol following high-dose administration to healthy volunteers revealed that the drug was rapidly absorbed and excreted unchanged in the urine with a half-life of 10 hours. Inhaled formoterol, as monotherapy or in combination with other agents, is an effective and safe treatment option for patients with moderate to severe COPD. Clinical studies have demonstrated improvements in lung function and COPD symptoms, particularly dyspnea; reductions in the risk of exacerbations; and improvement in patients' health status. The adverse event profile of inhaled formoterol is similar to that of placebo, with few adverse cardiovascular events. Formoterol is a valuable bronchodilator used in the maintenance treatment of COPD. This review describes the mechanism of action, pharmacodynamics, and pharmacokinetics of inhaled formoterol. It also reviews the results of large, randomized, controlled clinical trials that evaluated the use of formoterol as monotherapy and in combination with inhaled corticosteroids, long-acting muscarinic antagonists, and triple therapy regimens in the treatment of patients with moderate to severe COPD.
\end{abstract}

Keywords: formoterol fumarate, long-acting $\beta_{2}$-agonists, COPD, bronchodilator

\section{Plain Language Summary}

COPD leads to substantial illness and mortality in the older population and is characterized by uncomfortable or difficult breathing and frequent use of health-care resources. Bronchodilators represent a key treatment for patients with COPD because they help to open the airways and ease breathing. This effect reduces episodes of worsening COPD symptoms and may improve patients' quality of life. Formoterol is a bronchodilator that can be used alone or combined with other medicines that can improve lung function in patients with COPD. Many clinical studies have evaluated the efficacy and safety of formoterol in patients with different degrees of COPD symptoms and severity. These studies consistently show the benefits of formoterol and the ability to combine formoterol with other treatments that lead to further benefits without significant safety concerns. This article reviews the clinical studies and the scientific data about how formoterol affects and moves through the body. With decades of experience, formoterol is an important treatment option 
for patients with COPD to improve their symptoms and reduce the limitations and burdens of disease.

\section{Introduction}

Chronic obstructive pulmonary disease (COPD) is a major cause of morbidity and mortality that is currently the fourth leading cause of death in the world and was projected to be the third leading cause of death by $2020{ }^{1}$ Long-acting $\beta_{2}$-agonists (LABAs) such as formoterol are a mainstay of COPD treatment alone or in combination with long-acting muscarinic antagonists (LAMAs) and/or inhaled corticosteroids (ICS), depending on patients' symptoms and exacerbation history. ${ }^{1}$ Formoterol has been used to treat COPD since the early 1990s and has high selectivity and very high affinity for the $\beta_{2}$-adrenoceptor. ${ }^{2}$ Its long duration of action stems from the lipophilic and basic nature of the drug that allows it to remain in the airway smooth muscle over time. ${ }^{3}$ The longacting bronchodilators (LABAs and LAMAs) improve lung function, as measured by forced expiratory volume in 1 second $\left(\mathrm{FEV}_{1}\right)$, and reduce symptoms of disease by widening the airways and reducing the number of exacerbations. ${ }^{1}$ LAMAs are preferred as monotherapy for exacerbation prevention. The objectives of this review article are to describe the pharmacokinetics and pharmacodynamics of formoterol in relation to COPD and other $\beta_{2}$-agonists and to review clinical trial findings for efficacy and safety of formoterol alone and in fixed-dose combinations with ICS and/or LAMAs in patients with COPD.

\section{Pharmacokinetics and}

\section{Pharmacodynamics of Formoterol Description and Pharmacokinetics}

Formoterol is an inhaled, selective $\beta_{2}$-adrenergic receptor agonist formulated as the fumarate salt and as a racemic mixture of two enantiomers. ${ }^{2}$ Formoterol has relatively high water solubility and moderate lipophilicity, allowing rapid delivery to bronchial smooth muscle cells for rapid bronchodilation. ${ }^{2,3}$ From the depot within the smooth muscle, formoterol progressively leaches out to interact with the active site of the $\beta_{2}$-receptor, providing its prolonged duration of action. Plasma concentrations following therapeutic doses are very low and difficult to detect. Following inhalation of high-dose formoterol $(120 \mu \mathrm{g})$ in healthy volunteers, formoterol was rapidly absorbed, with a half-life of approximately 10 hours and urinary excretion of unchanged drug. ${ }^{4}$

\section{Preclinical Pharmacological Profile and Comparisons with Other $\beta_{2}$-Agonists}

Formoterol is highly bronchoselective and potent compared with other $\beta_{2}$-agonists (Table 1 ). ${ }^{3}$ In guinea pig trachea contracted with prostaglandin $\mathrm{F}_{2 \alpha}$, formoterol was approximately 50-fold and 27-fold more potent than salbutamol and salmeterol, respectively. ${ }^{5}$ Indeed, compared with salbutamol and salmeterol, formoterol was 10 - to 20 -fold more potent at inhibiting histamine-induced bronchoconstriction in conscious guinea pigs. ${ }^{5}$ In vitro studies of human airway smooth muscle fragments showed that formoterol relaxed the tissue in a concentration-dependent fashion and was the most potent compared with other $\beta_{2}$-agonists. ${ }^{5}$ Results from in vitro studies in human isolated bronchi indicate that formoterol has a greater maximal efficacy than olodaterol. ${ }^{6}$ Although vilanterol is more selective than formoterol for $\beta_{2^{-}}$versus $\beta_{1}$ - or $\beta_{3^{-}}$adrenoreceptors, formoterol exhibits greater $\beta_{2}$-adrenoreceptor intrinsic efficacy and functional potency. $^{7}$

\section{Onset and Duration of Action}

Formoterol relaxed both animal and human smooth muscle cells rapidly and comparably to salbutamol, whereas salmeterol was markedly slower. ${ }^{5}$ In patients with COPD, formoterol increased $\mathrm{FEV}_{1}$ within 5 minutes of inhalation (Figure 1), and the effect observed at this early time point

Table I Comparative Pharmacology and Pharmacokinetic Characteristics of LABAs

\begin{tabular}{|l|l|l|l|l|l|}
\hline Characteristic & Formoterol & Indacaterol & Olodaterol & Vilanterol & Salmeterol \\
\hline B2 agonism & Full agonist & Partial agonist & Nearly full agonist & Partial agonist & Partial agonist \\
Selectivity & $\beta_{2}>\beta_{3}>\beta_{1}$ & $\beta_{2}>\beta_{3}>\beta_{1}$ & $\beta_{2}>>\beta_{1}>\beta_{3}$ & $\beta_{2}>>\beta_{3}>\beta_{1}$ & $\beta_{2}>>\beta_{1}>\beta_{3}$ \\
Potency & ++ & + & ++ & ++ & + \\
Lipophilicity & ++ & +++ & ++ & +++ & +++ \\
Elimination half-life & $\sim 10$ hours & $40-56$ hours & 7.5 hours & 21 hours & 5.5 hours \\
Onset of action in COPD & Within 5 minutes & Within 5 minutes & Within 5 minutes & Within 5 minutes & $\sim 10$ minutes \\
Duration of action & 12 hours & 24 hours & $\geq 24$ hours & 22 hours & 12 hours \\
\hline
\end{tabular}

Note: Data from these studies. ${ }^{1,3-7,53-59}$

Abbreviations: COPD, chronic obstructive pulmonary disease; LABA, long-acting $\beta_{2}$-agonist. 
was $80 \%$ of the maximal effect of the drug. ${ }^{8}$ Formoterol exhibited faster onset of bronchodilator action within the first 2 hours of administration compared with tiotropium in patients with COPD. ${ }^{9}$ Fluticasone/formoterol had a faster onset of bronchodilator action compared with fluticasone/ salmeterol in patients with asthma; similarly, glycopyrronium/formoterol also had a faster onset of bronchodilator action compared with umeclidinium/vilanterol. ${ }^{10,11}$ The rapid onset of formoterol in combination with budesonide was confirmed in a study comparing the Turbuhaler ${ }^{\circledR}$ and Spiromax ${ }^{\circledR}$ devices in patients with COPD; ${ }^{12}$ these results are consistent with studies in patients with asthma. ${ }^{13,14}$ With regard to duration of effect, formoterol produced long-lasting inhibition of induced contraction in human bronchial tissues, suggesting retention within the tissues. ${ }^{2}$ The lipophilicity of formoterol and depot effects likely explain the long duration of action following inhalation. In patients with COPD, formoterol significantly improved spirometry over 12 hours. ${ }^{15}$

\section{Clinical Efficacy of Inhaled Formoterol in Patients with COPD}

Formoterol is available in a number of different products as monotherapy and in fixed-dose combinations (Table 2). Formoterol monotherapy was approved by the United States Food and Drug Administration (US FDA) in 2001 as an inhalation solution for use in a jet nebulizer, and in powder form for use with the Aerolizer ${ }^{\mathbb{R}}$ inhaler (which is no longer available). Fixed-dose combinations include budesonide and formoterol in a pressurized metered-dose inhaler (pMDI) approved in 2006, and glycopyrrolate and formoterol pMDI approved in 2016. The combination of aclidinium bromide and formoterol in a breath-actuated dry powder inhaler (DPI) was approved in 2019, and, more recently, formoterol has been added as a component in triple therapy combinations. Formulations of extrafine particles enable delivery of the drugs to the small airways, thus reducing the dose necessary to achieve efficacy. ${ }^{16}$

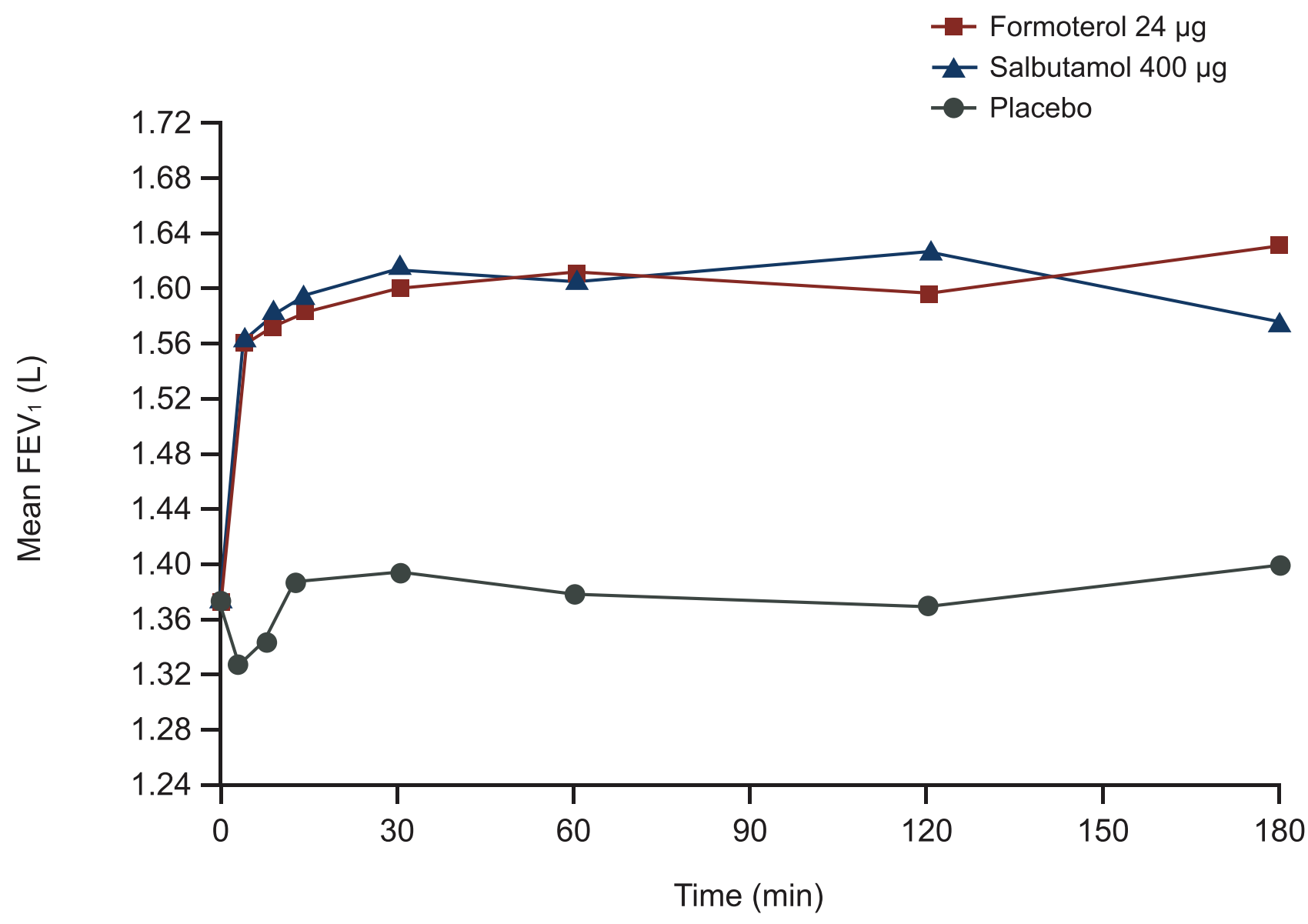

Figure I The bronchodilator effect of formoterol occurs rapidly. A single inhalation of medication was administered to 24 patients with stable COPD in a randomized, three-way, crossover study. Reprinted from Respiratory Medicine, Vol 95 (I0), Benhamou et al, Rapid onset of bronchodilation in COPD: a placebo-controlled study comparing formoterol (Foradil Aerolizer) with salbutamol (Ventodisk), pages 817-82I, Copyright 200I, with permission from Elsevier. ${ }^{8}$

Abbreviations: COPD, chronic obstructive pulmonary disease; $\mathrm{FEV}_{1}$, forced expiratory volume in I second. 
Table 2 Available Formoterol Products

\begin{tabular}{|c|c|c|c|c|}
\hline Formoterol Products & Brand Name & $\begin{array}{l}\text { Delivery } \\
\text { Method }\end{array}$ & Approvals & Dosage \\
\hline \multicolumn{5}{|l|}{ Monotherapy products } \\
\hline Formoterol & Atimos Modulite ${ }^{\circledR}$ & pMDI & EU & $\begin{array}{l}\text { I } 2 \mu \mathrm{g} \text { BID; up to } 4 \text { inhalations daily for severe } \\
\text { COPD }\end{array}$ \\
\hline Formoterol inhalation powder ${ }^{a}$ & Foradil Aerolizer $^{\circledR}$ & $\begin{array}{l}\text { Capsule used } \\
\text { with Aerolizer } \\
\text { inhaler }\end{array}$ & $\begin{array}{l}\text { US 200I } \\
\text { EU }\end{array}$ & $12 \mu \mathrm{g}$ every 12 hours \\
\hline Formoterol inhalation solution & Perforomist ${ }^{\circledR}$ & Nebulizer & US 2001 & One $20 \mu g / 2 \mathrm{~mL}$ vial every 12 hours \\
\hline \multicolumn{5}{|l|}{ Combination with corticosteroid } \\
\hline Mometasone-formoterol & Dulera $^{\circledR}$ & pMDI & $\begin{array}{l}\text { US } 2010 \\
\text { (asthma } \\
\text { only) }\end{array}$ & No COPD indication \\
\hline Beclomethasone-formoterol & $\begin{array}{l}\text { Fostair }^{\circledR}(\text { EU) } \\
\text { Fostex }^{\circledR} \text { (Poland) }\end{array}$ & PMDI and DPI & EU & $\begin{array}{l}\text { 100/6 } \mu \mathrm{g} \text { per inhalation; } 2 \text { inhalations BID } \\
\text { 100/6 } \mu \mathrm{g} \text { per inhalation (dosing frequency not } \\
\text { specified) }\end{array}$ \\
\hline \multirow[t]{3}{*}{ Budesonide-formoterol } & Symbicort $^{\circledR}$ & pMDI & US 2006 & I60/4.5 $\mu \mathrm{g}$ per inhalation; 2 inhalations BID \\
\hline & Symbicort Turbohaler ${ }^{\circledR}$ & DPI & EU 2014 & $200 / 6 \mu g$ per inhalation; 2 inhalations BID \\
\hline & Fobumix Easyhaler ${ }^{\circledR}$ & DPI & EU 2016 & I60/4.5 $\mu \mathrm{g}$ per inhalation; 2 inhalations BID \\
\hline \multicolumn{5}{|l|}{ Combination with LAMA } \\
\hline Glycopyrrolate-formoterol & Bevespi & pMDI (co- & US 2016 & 9/4.8 $\mu \mathrm{g}$ per inhalation; 2 inhalations BID \\
\hline & AEROSPHERE ${ }^{\circledR}$ & $\begin{array}{l}\text { suspension } \\
\text { technology) }\end{array}$ & EU 2018 & \\
\hline \multirow[t]{2}{*}{ Aclidinium-formoterol } & Duaklir Pressair ${ }^{\circledR}$ & DPI & US 2019 & $400 / / 2 \mu \mathrm{g}$ per inhalation; I inhalation BID \\
\hline & Duaklir Genuair ${ }^{\circledR}$ & DPI & EU 2014 & $340 / 12 \mu \mathrm{g}$ per inhalation; I inhalation BID \\
\hline \multicolumn{5}{|l|}{ Triple therapy (LABA, LAMA, ICS) } \\
\hline $\begin{array}{l}\text { Budesonide-glycopyrrolate- } \\
\text { formoterol }\end{array}$ & $\begin{array}{l}\text { Breztri } \\
\text { AEROSPHERE }^{\circledR}\end{array}$ & PMDI & US 2020 & 160/9/4.8 $\mu \mathrm{g}$ per inhalation; 2 inhalations BID \\
\hline $\begin{array}{l}\text { Beclomethasone-formoterol- } \\
\text { glycopyrronium }\end{array}$ & Trimbow $^{\circledR}$ & PMDI & EU 2017 & 100/6/10 $\mu \mathrm{g}$ per inhalation; 2 inhalations BID \\
\hline
\end{tabular}

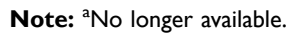

Abbreviations: BID, twice daily; COPD, chronic obstructive pulmonary disease; DPI, dry powder inhaler; EU, European Union; ICS, inhaled corticosteroid; LABA, long-acting $\beta_{2}$-agonist; LAMA, long-acting muscarinic antagonist; pMDI, pressurized metered-dose inhaler; US, United States.

\section{Formoterol Monotherapy}

Bronchodilator therapy with LABA or LAMA monotherapy is recommended as initial treatment for Group A and B patients according to the Global Initiative for Chronic Obstructive Lung Disease (GOLD) guidelines. ${ }^{1}$ A 2013 meta-analysis identified 14 studies of formoterol $12 \mu \mathrm{g}$ twice daily (BID) versus placebo, of which three studies also included a formoterol $24 \mu \mathrm{g}$ BID group and one study evaluated only formoterol $24 \mu \mathrm{g} \mathrm{BID} .{ }^{17}$ Most studies used a DPI (ie, Turbuhaler $^{\circledR}$ ) to deliver formoterol. Severe COPD exacerbations were reduced by therapy with formoterol $12 \mu \mathrm{g}$ (odds ratio [OR], 0.75; 95\% confidence interval $[\mathrm{CI}], 0.55-1.02$; $\mathrm{p}=0.064)$ and $24 \mu \mathrm{g}$ (OR, 0.28; 95\% CI, 0.11-0.73; $\mathrm{p}=0.0092) .{ }^{17}$ The mean difference in trough $\mathrm{FEV}_{1}$ versus placebo across studies was $45 \mathrm{~mL}$ with formoterol $12 \mu \mathrm{g}$ BID. ${ }^{17}$ In a 12-week, randomized, double-blind trial, formoterol via inhalation solution $(20 \mu \mathrm{g} / 2 \mathrm{~mL})$ and via DPI $(12 \mu \mathrm{g})$ demonstrated similar efficacy. ${ }^{18}$

\section{Formoterol in Dual Combination with ICS}

For patients with moderate to very severe COPD, combination therapy with LABA and ICS is recommended as an optional treatment for patients with a high risk of COPD exacerbations and elevated eosinophils. ${ }^{1}$ Triple therapy represents another treatment option, particularly for 


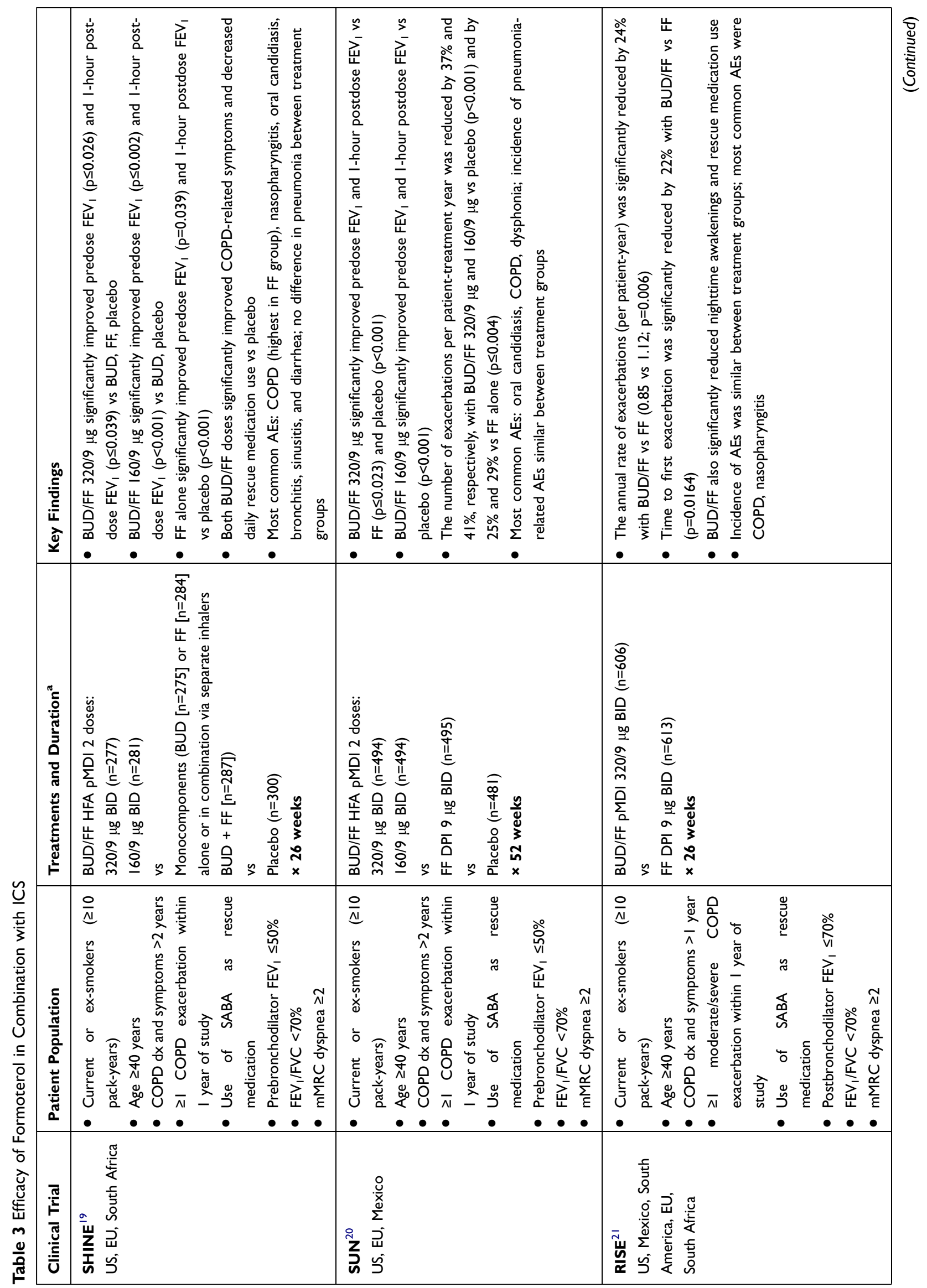




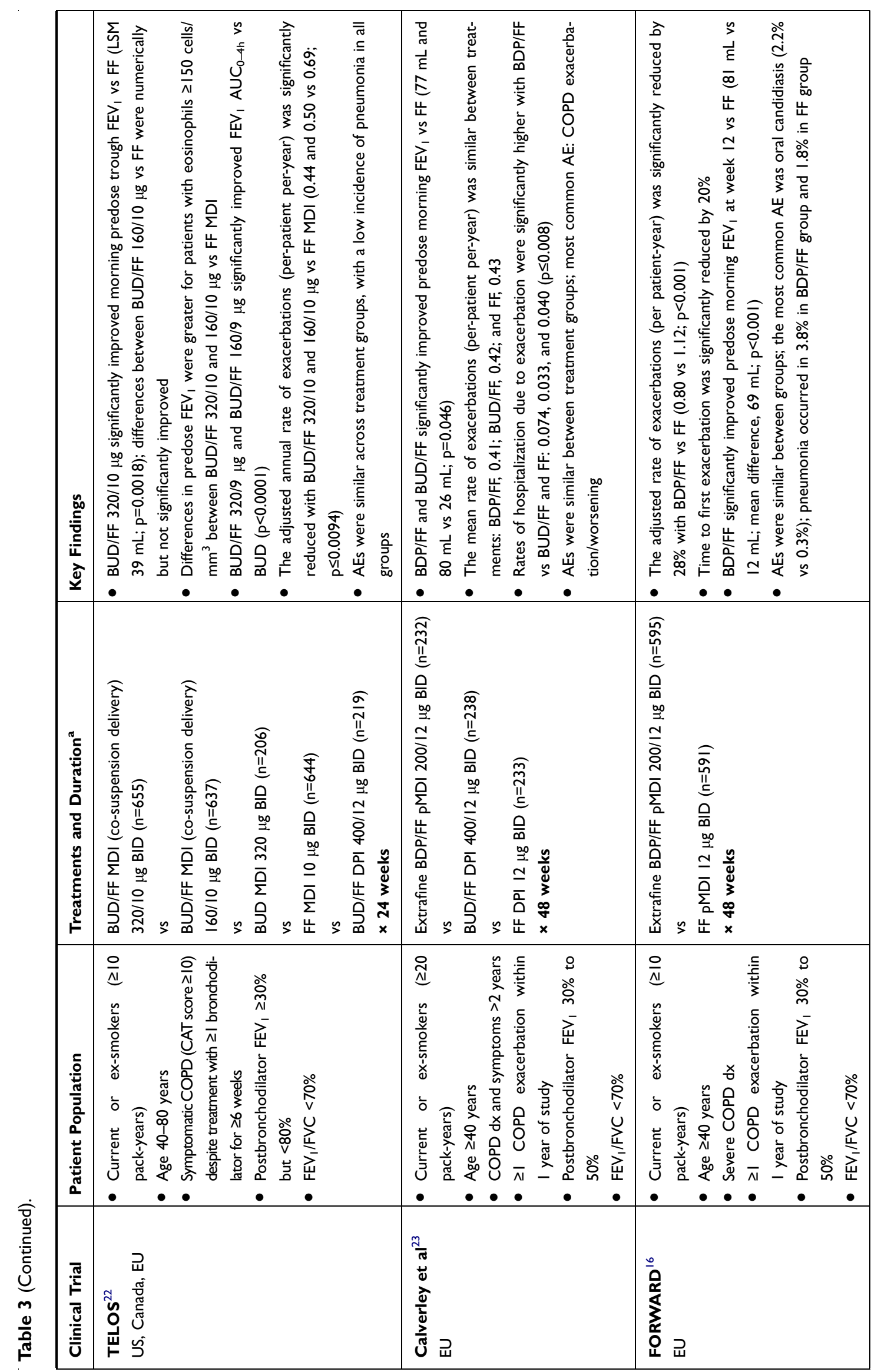




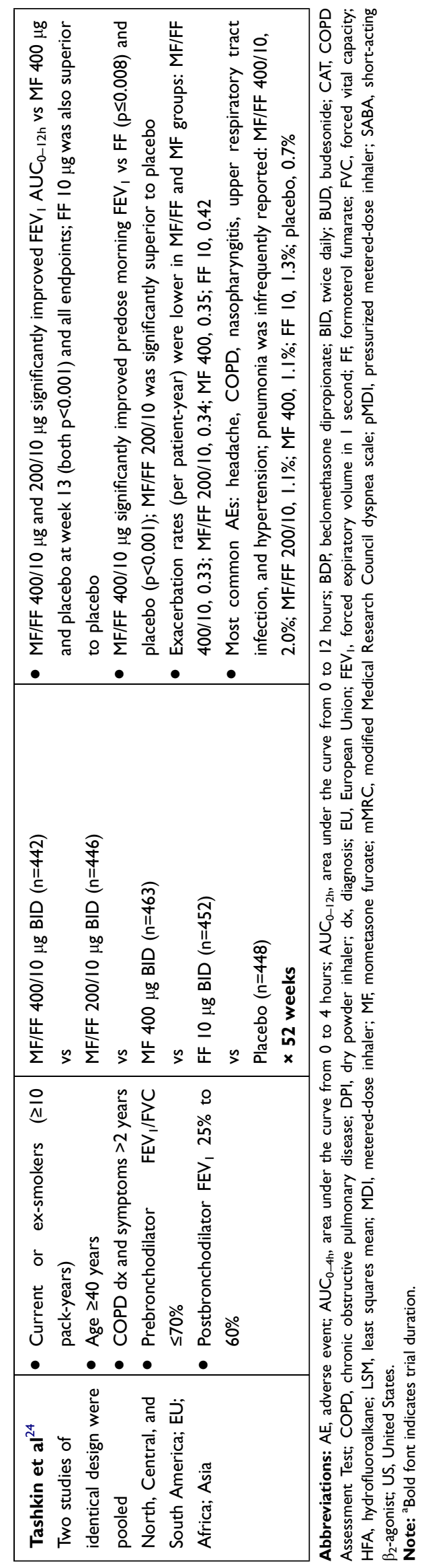

patients with a high risk of exacerbations and elevated eosinophil levels, as discussed below. ${ }^{1}$ Table 3 summarizes key clinical studies of formoterol/ICS combination therapy. Two similarly designed, pivotal clinical studies were conducted to evaluate the combination of budesonide and formoterol pMDI administered in two dosage strengths (budesonide/formoterol 320/9 $\mu \mathrm{g}$ BID and 160/9 $\mu \mathrm{g}$ BID). ${ }^{19,20}$ Patients with moderate to very severe COPD were enrolled based on the presence of symptoms for $>2$ years, including a modified Medical Research Council dyspnea scale score $\geq 2$, history of $\geq 1$ COPD exacerbations treated with a course of oral corticosteroids and/or antibiotics within 1 year of screening, and prebronchodilator $\mathrm{FEV}_{1} \leq 50 \%$ of predicted normal. In the SHINE study (NCT00206154), budesonide/formoterol pMDI 320/9 $\mu \mathrm{g}$ demonstrated significantly greater improvements in lung function compared with the individual components as monotherapy over 6 months. ${ }^{19}$ The second study, SUN (NCT00206167), confirmed the significant benefit of budesonide/formoterol pMDI 320/9 $\mu \mathrm{g}$ on lung function, in addition to demonstrating a significant reduction in the rate of COPD exacerbations for both budesonide/formoterol dose groups versus formoterol alone and placebo. ${ }^{20}$ The RISE study (NCT02157935) further evaluated the effect of budesonide/formoterol pMDI on the rate of COPD exacerbations as defined by the US FDA guidance (ie, worsening of $\geq 2$ major symptoms or 1 major symptom in combination with $\geq 1$ minor symptom for $\geq 2$ consecutive days and requiring treatment with systemic corticosteroid for $\geq 3$ days and/or antibiotics [moderate] and/or hospitalization [severe]). ${ }^{21}$ Budesonide/formoterol pMDI 320/9 $\mu \mathrm{g}$ significantly reduced the annual rate of moderate and severe exacerbations by $24 \%(\mathrm{p}=0.006)$ and significantly reduced the risk for time to first moderate or severe exacerbation compared with formoterol DPI $(\mathrm{p}=0.016$; Figure 2).

AEROSPHERETM inhalers using co-suspension delivery technology were developed to enhance delivery of medication by pMDI to the whole lung and minimize the effects of patient handling errors. ${ }^{22}$ The TELOS study (NCT02766608) compared 24 weeks of randomized therapy with one of two doses of budesonide/formoterol pMDI (320/10 $\mu \mathrm{g}$ and $160 / 10 \mu \mathrm{g}$ BID) to monocomponents formoterol pMDI $10 \mu \mathrm{g}$ or budesonide pMDI $320 \mu \mathrm{g}$ (all delivered by single-dose AEROSPHERETM inhaler), and open-label budesonide/formoterol DPI 400/12 $\mu \mathrm{g} .{ }^{22}$ Enrolled patients had symptomatic, moderate to very severe COPD, with no requirement for a history of 


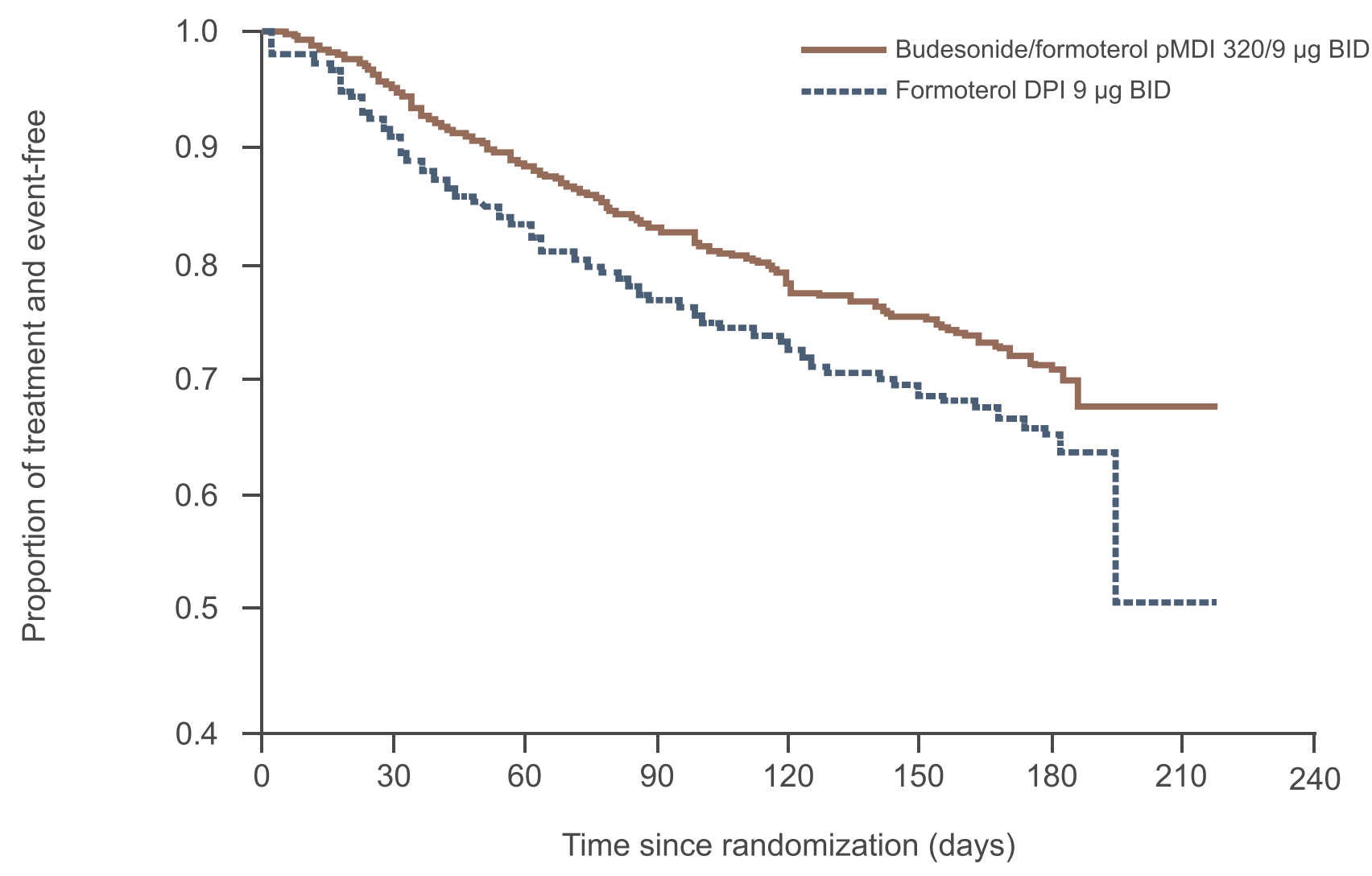

\begin{tabular}{|c|c|c|c|c|c|c|c|c|}
\hline$B / f n=$ & 605 & 564 & 516 & 83 & 447 & 429 & 09 & \\
\hline $\mathrm{F} \mathrm{n}=$ & 613 & 530 & 484 & 436 & 406 & 377 & 178 & 2 \\
\hline
\end{tabular}

Figure 2 Time to first moderate or severe exacerbation ${ }^{\mathrm{a}}$ in the RISE study.

Notes: ${ }^{a}$ Between-treatment difference in time to first moderate or severe exacerbation, $\mathrm{p}<0.016$; Cox regression model. Reprinted from Respiratory Medicine, Vol I32, Ferguson et al, Effect of budesonide/formoterol pressurized metered-dose inhaler on exacerbations versus formoterol in chronic obstructive pulmonary disease: the 6-month, randomized RISE (Revealing the Impact of Symbicort in reducing Exacerbations in COPD) study, pages 3I-4I, Copyright 20I7, with permission from Elsevier. ${ }^{21}$ Abbreviations: B/f, budesonide/formoterol; BID, twice daily; DPI, dry powder inhaler; f, formoterol; pMDI, pressurized metered-dose inhaler.

COPD exacerbations. A dose response favoring the higher dosage 320/10 $\mu \mathrm{g}$ pMDI was observed for improvements in lung function and exacerbation outcomes. The budesonide/formoterol pMDI $320 / 10 \mu \mathrm{g}$ was noninferior to the budesonide/formoterol DPI formulation.

Formoterol has also been studied in other ICS combinations. Calverley and colleagues evaluated treatment with extrafine beclomethasone dipropionate (BDP) plus formoterol compared with formoterol alone for 48 weeks and found that combination therapy improved lung function and symptoms versus monotherapy. ${ }^{23}$ In the FORWARD study (NCT00929851), extrafine BDP/formoterol pMDI significantly reduced the exacerbation rate (rate ratio: $0.72 ; \mathrm{p}<0.001)$ and improved predose morning $\mathrm{FEV}_{1}$ (mean difference at week 12, $69 \mathrm{~mL} ; \mathrm{p}<0.001$ ) compared with formoterol alone. ${ }^{16}$ The efficacy and safety of the combination of mometasone furoate (MF) and formoterol in two dosage strengths administered by pMDI (400/10 $\mu \mathrm{g}$ and $200 / 10 \mu \mathrm{g}$ ) were evaluated in two randomized, 52-week, placebo-controlled studies. ${ }^{24} \mathrm{MF}$ plus formoterol demonstrated dose-dependent improvements in lung function; both doses reduced exacerbations and improved respiratory health status compared with placebo. $^{24}$ However, the fixed-dose combination of MF/formoterol is not approved for the treatment of COPD.

\section{Formoterol in Combination with LAMA}

According to guidelines from GOLD, LAMA/LABA combination therapy is currently recommended for patients with COPD who do not respond to initial monotherapy, either because of persistent dyspnea or exacerbations. ${ }^{1}$ The Phase III PINNACLE studies compared the combination of glycopyrrolate and formoterol (GFF) formulated for the AEROSPHERE ${ }^{\mathrm{TM}}$ inhaler using co-suspension delivery in 


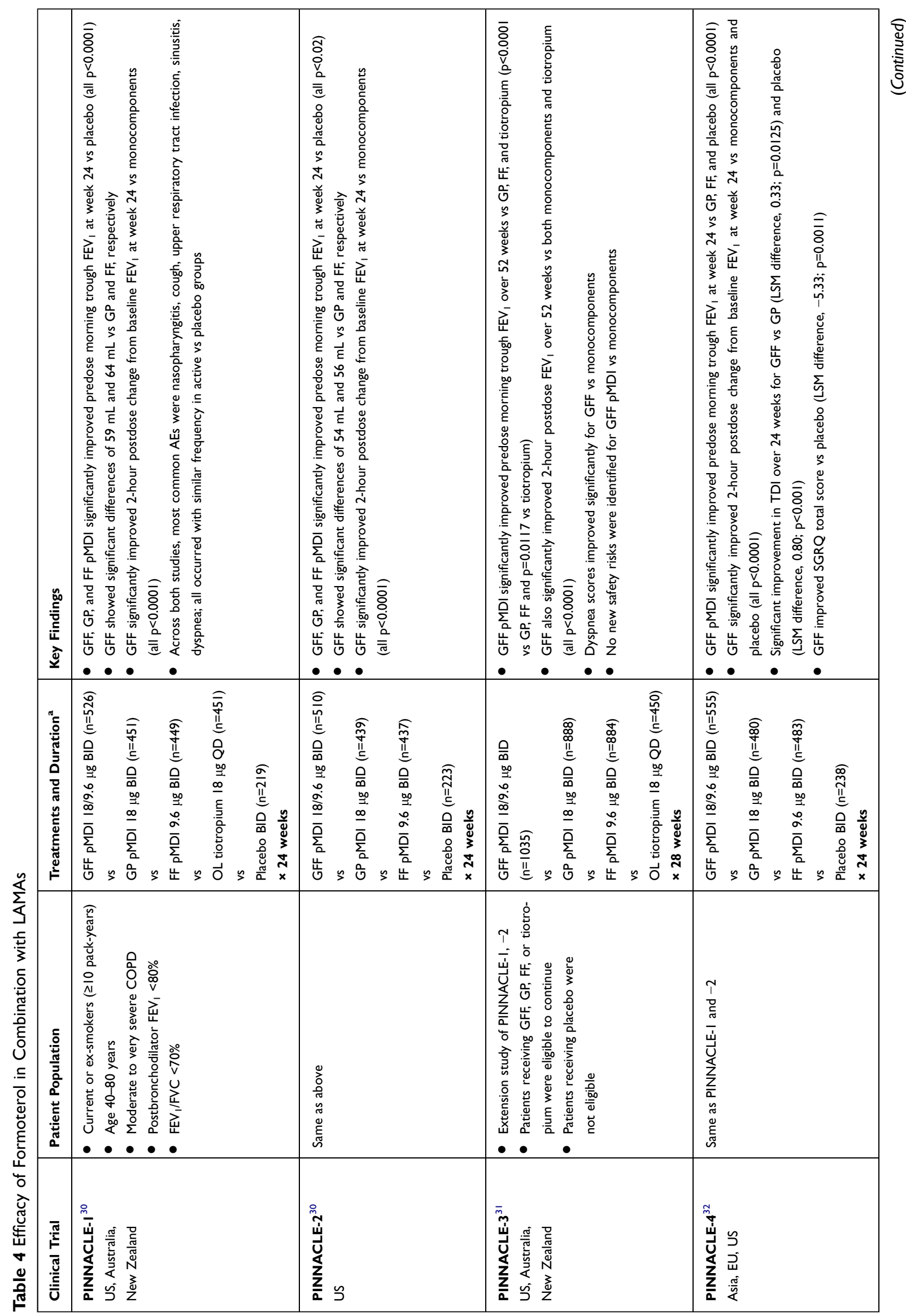




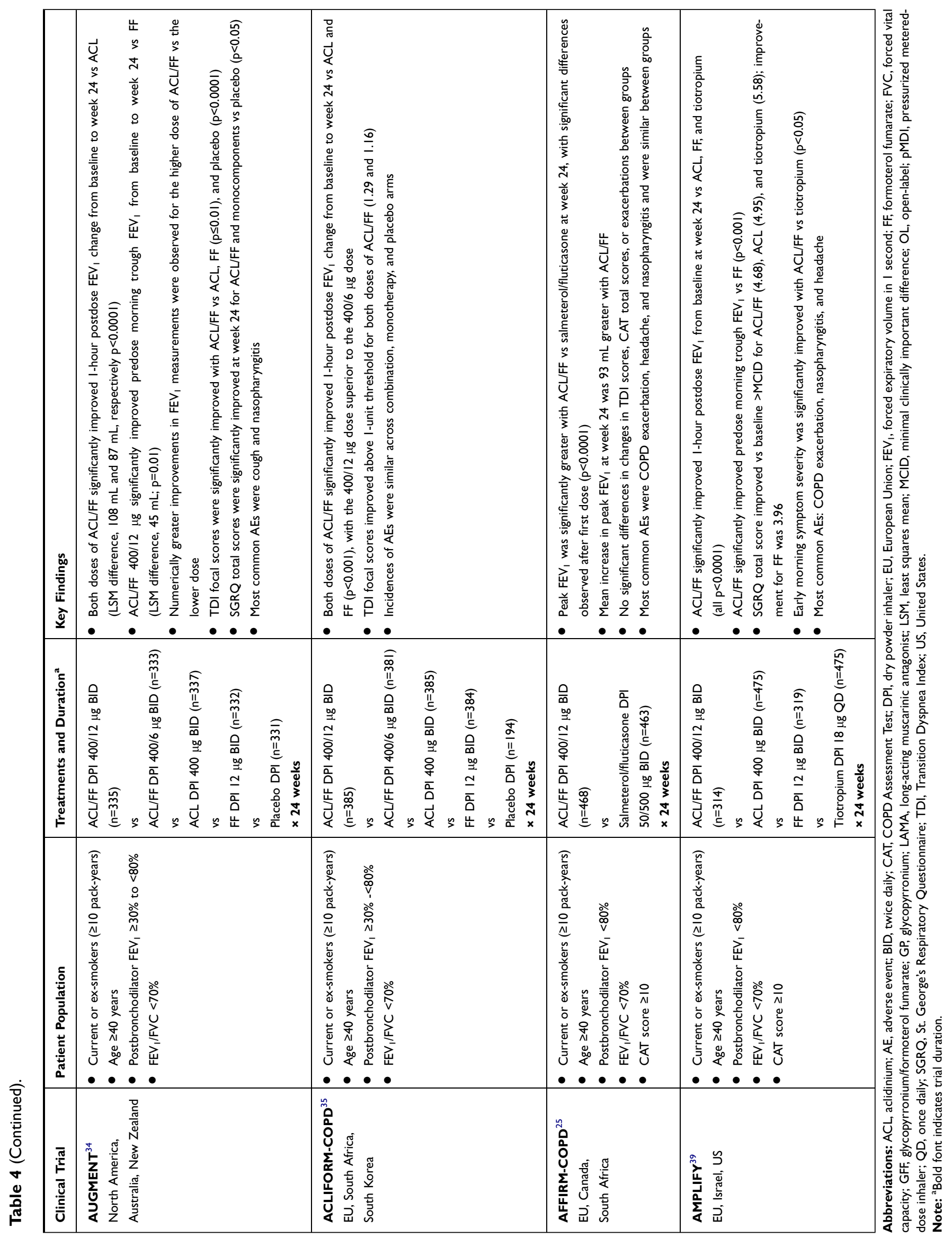


a pMDI with its monocomponents and placebo (Table 4). ${ }^{25}$ The fixed-dose GFF pMDI formulation demonstrated lasting stability, dose uniformity, and pharmacokinetics that fell within bioequivalence bounds for the monocomponents (Figure 3). ${ }^{26}$ Phase II dose-ranging studies determined the dose of GFF to be used in combination, although they did not show a dose-response relationship for increasing doses of glycopyrrolate. ${ }^{27-29}$

The pivotal registration trials PINNACLE-1 and -2 (NCT01854645 and NCT01854658, respectively) enrolled patients with moderate to very severe COPD but did not require them to be symptomatic or have a recent exacerbation history. ${ }^{30}$ Both studies demonstrated greater benefits on lung function with combination therapy versus the monocomponents and placebo. The PINNACLE-3 (NCT01970878) trial was a 28-week extension study of PINNACLE-1 and $-2 .^{31}$ Results of the study showed that GFF pMDI BID maintained lung function improvements over 52 weeks versus its monocomponents without additional safety risk (Figure 4).
GFF was also determined to be noninferior to open-label tiotropium. To evaluate the efficacy and safety of GFF pMDI in other populations, the PINNACLE-4 (NCT02343458) trial included Asian and European patients. $^{32}$ In this population, GFF pMDI improved lung function and symptoms as well as patient-reported outcomes compared with placebo and glycopyrrolate pMDI. To determine the benefit of GFF combination therapy in patients with COPD who had a low symptom burden, a pooled analysis was conducted of patients from PINNACLE-1, -2 , and -4 who met GOLD category A criteria (ie, COPD Assessment Test [CAT] score $<10$ and either no exacerbations or 1 exacerbation that did not lead to hospitalization in the previous year). ${ }^{33}$ Fifteen percent of the patients in the pooled population were GOLD category A, and GFF pMDI improved lung function to a magnitude comparable to that observed in the overall population.

Another LAMA used in combination with formoterol is aclidinium, and several studies have evaluated a fixed-dose

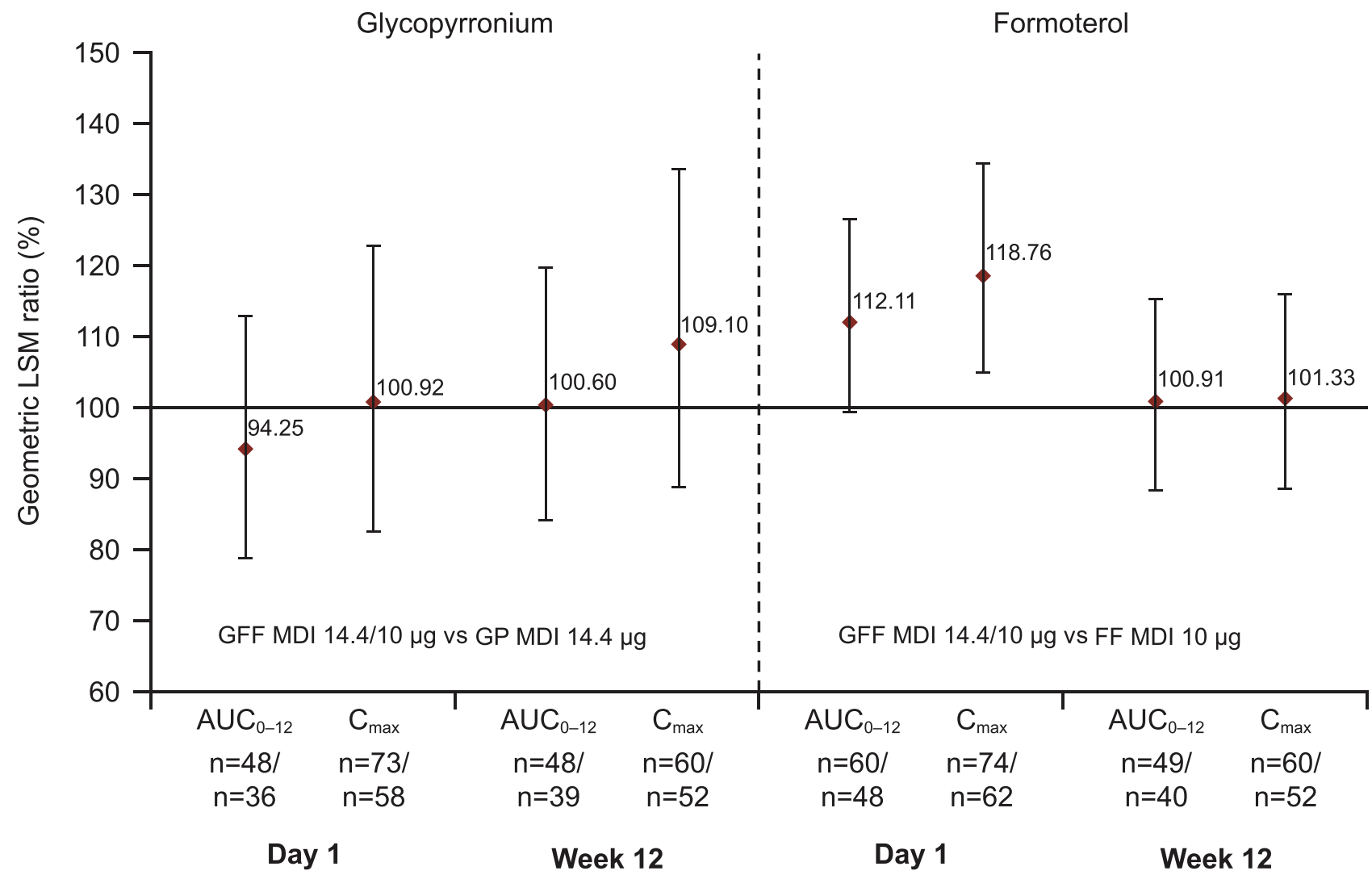

Figure 3 Relative bioavailability for glycopyrronium/formoterol combination versus glycopyrronium or formoterol monotherapy. Reprinted from International Journal of Chronic Obstructive Pulmonary Disease, Vol I3, Ferguson et al, Pharmacokinetics of glycopyrronium/formoterol fumarate dihydrate delivered via metered-dose inhaler using cosuspension delivery technology in patients with moderate-to-very severe COPD, pages 945-593, Copyright 2018, with permission from Dove Medical Press. ${ }^{26}$ Abbreviations: $\mathrm{AUC}_{0-12}$, area under the curve from 0 to 12 hours; $\mathrm{C}_{\max }$, maximum concentration achieved; FF, formoterol fumarate; GFF, glycopyrronium/formoterol fumarate; GP, glycopyrronium; LSM, least squares mean; MDI, metered-dose inhaler. 


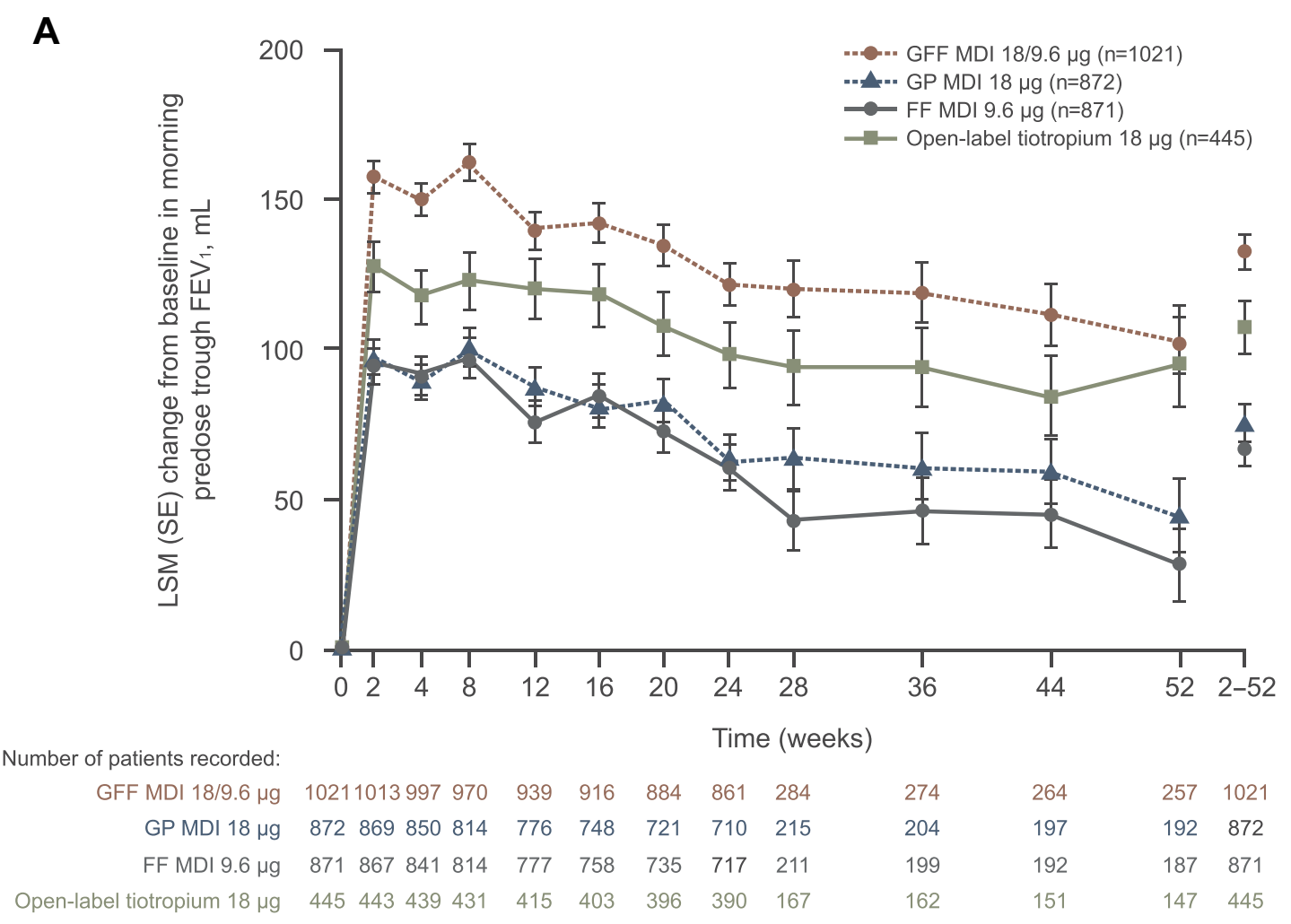

\section{B}

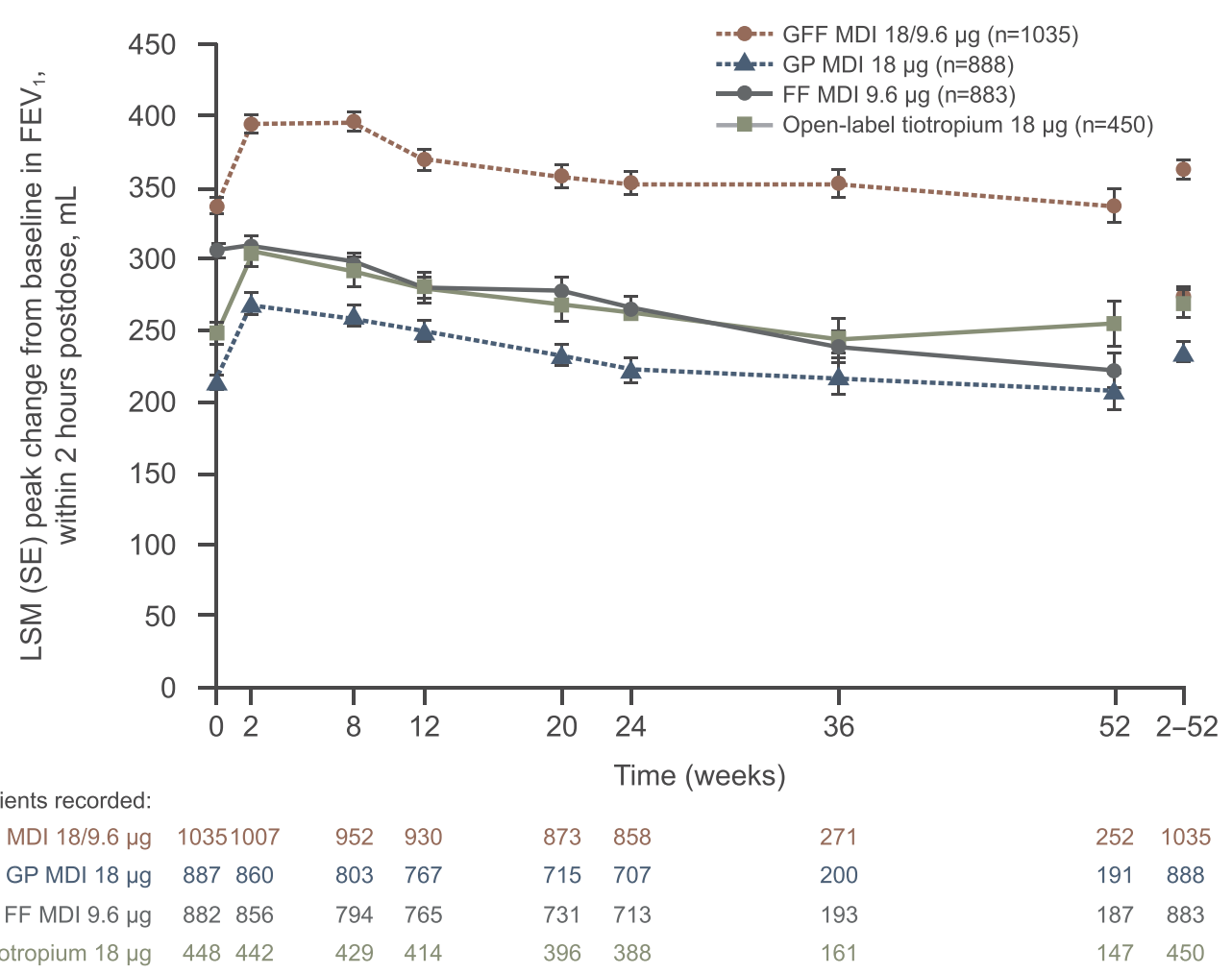

Figure 4 Effects of fixed-dose glycopyrrolate/formoterol combination on change from baseline in (A) Predose morning trough FEV , and (B) Peak change in FEV , within 2 hours postdose over 52 weeks versus monocomponents and open-label tiotropium. Reprinted from Respiratory Medicine, Vol I26, Hanania et al, Long-term safety and efficacy of glycopyrrolate/formoterol metered-dose inhaler using novel Co-Suspension ${ }^{\mathrm{TM}}$ Delivery Technology in patients with chronic obstructive pulmonary disease, pages I05-II5, Copyright 2017, with permission from Elsevier. ${ }^{31}$

Abbreviations: $\mathrm{FEV}_{1}$, forced expiratory volume in I second; FF, formoterol fumarate; GFF, glycopyrrolate/formoterol fumarate; GP, glycopyrronium; LSM, least squares mean; MDI, metered-dose inhaler; SE, standard error. 


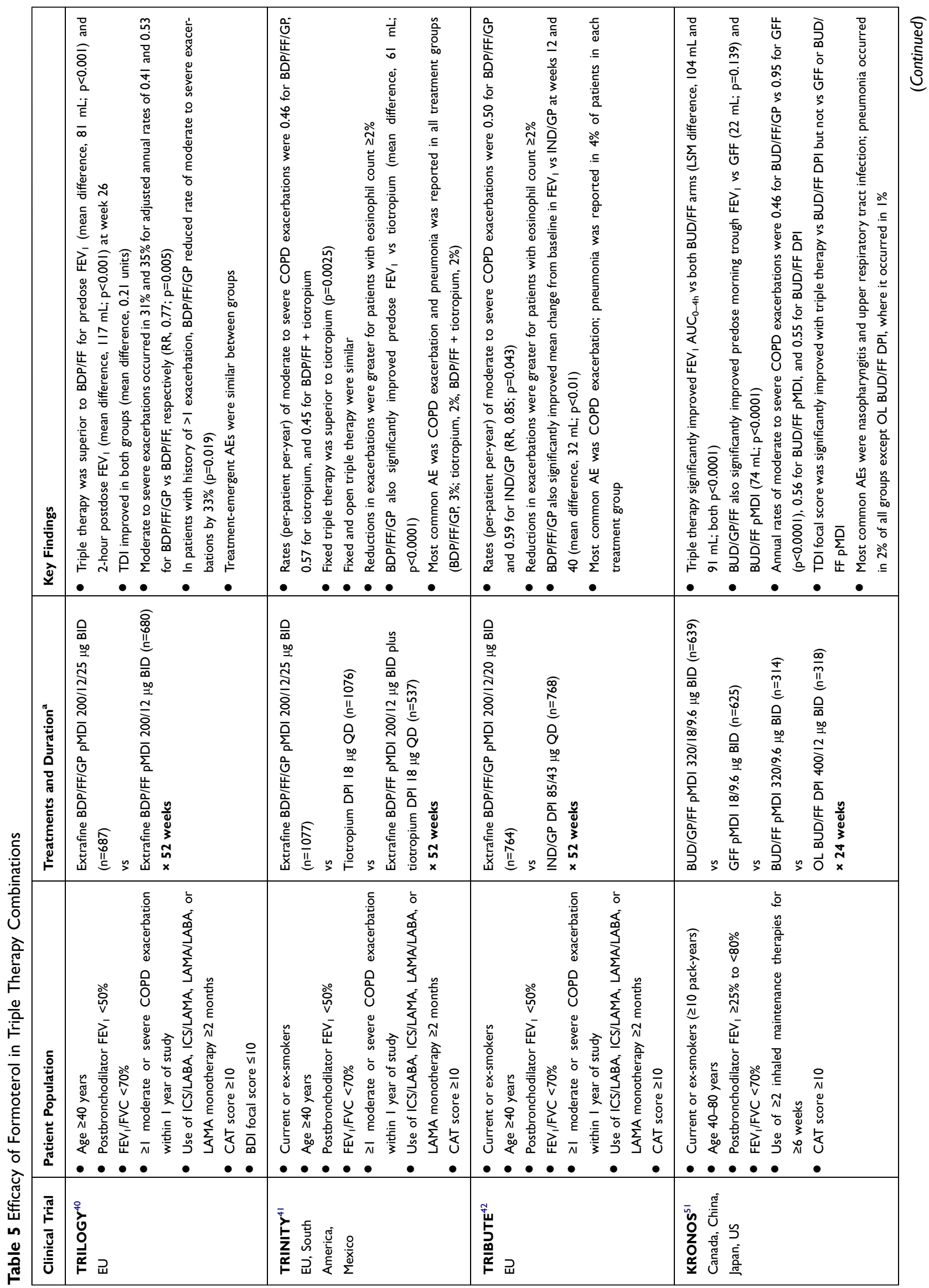




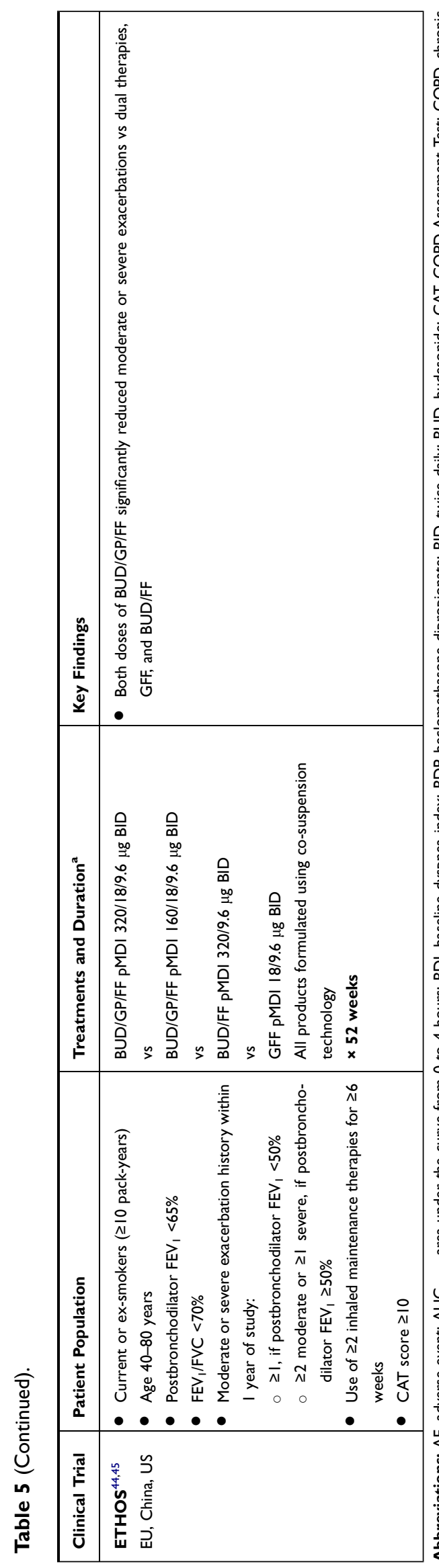

combination of these drugs in patients with COPD (Table 4). The AUGMENT and ACLIFORM-COPD studies (NCT01437397 and NCT01462942, respectively) demonstrated greater improvements in lung function for aclidinium/formoterol combination therapy compared with either component as monotherapy and with placebo. ${ }^{34,35}$ Greater improvements were observed with the higher dose of aclidinium/formoterol (400/12 $\mu \mathrm{g}$ BID vs 400/6 $\mu \mathrm{g}$ BID), but both doses provided clinically meaningful improvement ( $\geq 1$ unit) in Transition Dyspnea Index (TDI) focal score versus placebo. Several analyses were conducted using pooled data from the AUGMENT and ACLIFORM-COPD studies. In a prespecified analysis of symptoms and exacerbations, aclidinium/formoterol 400/12 $\mu \mathrm{g}$ significantly improved symptom control over 24 hours compared with its monocomponents and placebo and reduced the frequency of moderate or severe exacerbations by $29 \%$ versus placebo $(\mathrm{p}<0.05) .{ }^{36}$ The fixed-dose combination of aclidinium and formoterol also provided consistent improvements in patients with more and fewer symptoms based on the Baseline Dyspnea Index and the Evaluating Respiratory Symptoms (E-RS) in COPD diary. ${ }^{37}$ Patient subgroups according to airflow obstruction severity, age, sex, and exacerbation history were also evaluated using pooled AUGMENT and ACLIFORM-COPD data. ${ }^{38}$ This analysis showed that combination therapy was more effective than placebo across all subgroups.

In the AFFIRM-COPD study (NCT01908140), aclidinium/formoterol was compared with salmeterol/fluticasone, and the LAMA/LABA combination demonstrated superiority for peak $\mathrm{FEV}_{1}$ but similar results for dyspnea, health status, and exacerbation risk. ${ }^{25}$ The AMPLIFY study (NCT02796677) demonstrated that twice daily aclidinium/formoterol significantly improved 1-hour postdose $\mathrm{FEV}_{1}$ compared with the monocomponents and tiotropium, and combination therapy also improved early morning symptom control compared with tiotropium. ${ }^{39}$

\section{Triple Therapy Regimens Containing Formoterol}

Patients who have persistent breathlessness or exercise limitation or who are at risk for an exacerbation on ICS/ LABA or LAMA/LABA treatment can step up to triple therapy that combines medicines from all three pharmacological categories. ${ }^{1}$ Several clinical trials have evaluated triple therapy combinations including formoterol with various other components (Table 5).

The TRILOGY study (NCT01917331) compared a single-inhaler combination of extrafine beclomethasone 
dipropionate, formoterol fumarate, and glycopyrronium bromide $(\mathrm{BDP} / \mathrm{FF} / \mathrm{GB})$ with beclomethasone dipropionate and formoterol fumarate $(\mathrm{BDP} / \mathrm{FF})$ in patients with postbronchodilator $\mathrm{FEV}_{1}<50 \%$ and $\geq 1$ moderate to severe COPD exacerbation in the previous year. ${ }^{40}$ Triple therapy demonstrated significant improvements in $\mathrm{FEV}_{1}$ but not dyspnea at week $26 .^{40}$ The annual exacerbation rate was reduced by $23 \%$ with triple therapy. The TRINITY study (NCT01911364) compared extrafine BDP/FF/GB (fixed triple), tiotropium, and $\mathrm{BDP} / \mathrm{FF}$ plus tiotropium (open triple) and found exacerbation rates of $0.46,0.57$, and 0.45 , respectively. ${ }^{41}$ The fixed-dose triple therapy was superior to tiotropium for exacerbations and predose $\mathrm{FEV}_{1}$ and noninferior to open triple therapy. In the TRIBUTE study (NCT02579850), the effects of BDP/ $\mathrm{FF} / \mathrm{GB}$ in a single inhaler were compared with those of dual bronchodilators using indacaterol and glycopyrrolate. $^{42}$ The rate of moderate to severe COPD exacerbations over 52 weeks was reduced by $15 \%$ with triple therapy $(p=0.043)$, with a greater relative effect in patients with blood eosinophils $>2 \%$.

The KRONOS study (NCT01349803) compared budesonide/glycopyrrolate/formoterol fumarate (BUD/GP/FF) pMDI with several dual therapies and found a significant improvement in $\mathrm{FEV}_{1}$ area under the curve from 0 to 4 hours with triple therapy compared with budesonide-based dual therapies. ${ }^{43}$ Unlike other studies of triple therapy, KRONOS did not restrict the population based on history of exacerbations. In this population, the triple therapy regimen significantly reduced exacerbation rates versus dual therapy with glycopyrrolate and formoterol pMDI, thus supporting the use of triple therapy for patients with lower exacerbation risk. In the ETHOS study (NCT02465567), two different doses of budesonide were used in triple therapy regimens and compared with two dual therapy regimens, budesonide plus formoterol and glycopyrrolate plus formoterol. ${ }^{44}$ The recently published study indicates a significant reduction in the rate of moderate to severe exacerbations with triple therapy using high- and low-dosage budesonide plus glycopyrrolate and formoterol compared with dual therapy. ${ }^{44,45}$

\section{Safety of Inhaled Formoterol in Patients with COPD}

In formoterol monotherapy studies, the most common adverse events (AEs) were headache, nausea, diarrhea, COPD exacerbation, dizziness, and cough. ${ }^{18}$ Studies comparing various combination therapies generally found similar rates of AEs between treatment groups (Tables 4 and 5), and most events were mild or moderate in severity. As an adrenergic receptor agonist, concerns regarding cardiovascular AEs have been raised with LABA treatment, and cardiovascular disease is the most prevalent comorbidity in patients with COPD. ${ }^{46}$ Neither mode of formoterol monotherapy (DPI or inhalation solution) has been shown to have clinically meaningful effects on mean or maximum heart rate, most likely resulting from its selectivity for the $\beta_{2}$-receptor. ${ }^{18}$ Studies investigating the long-term effects of LABAs on heart rate and blood pressure over 48 weeks in $>3000$ patients with COPD showed small quantitative changes in heart rate compared with baseline that were numerically lower with LABA versus placebo, and blood pressure decreased with all treatments. $^{46}$ Two studies found no effects of therapeutic and supratherapeutic dosages of glycopyrrolate/formoterol pMDI using co-suspension delivery technology on cardiovascular parameters. $^{43}$

The US FDA had concerns about high-dose formoterol based on a 2003 review of three studies that found more frequent serious asthma exacerbations in patients receiving formoterol $24 \mu \mathrm{g}$ BID compared with those receiving placebo. $^{47}$ The FDA concluded that this finding was consistent with previously published, placebo-controlled, randomized trials of another LABA, salmeterol. In response, the FDA required a black box warning on all LABA and ICS/LABA combination products about possible AEs of LABAs in patients with asthma. Subsequently, four large, 26-week safety trials were conducted to evaluate the risk of serious asthma-related events associated with the use of ICS/LABA combination therapy. ${ }^{48}$ These trials demonstrated noninferiority of ICS/LABA compared with ICS alone in risk of hospitalizations, intubations, and deaths related to asthma. The black box warning was removed from the ICS/LABA products in 2017; however, this language is still included in the warnings and precautions section of the label.

In patients with COPD, the use of formoterol in combination with ICS may be associated with several other specific AEs, including pneumonia, changes in bone mineral density, and ophthalmologic events. ${ }^{49}$ The incidence of pneumonia varies for several reasons, including severity of COPD, exacerbation history, and specific ICS used. ${ }^{49}$ The PATHOS study (NCT01146392) showed an approximately $75 \%$ greater risk of pneumonia with fluticasone/salmeterol compared with budesonide/formoterol. ${ }^{50}$ Pneumonia occurred at similar rates among patients receiving 
budesonide/formoterol, formoterol monotherapy, and placebo in the SUN and SHINE studies, ${ }^{19,20}$ as well as with triple therapy compared with LAMA/LABA therapy in the KRONOS study. ${ }^{51}$

Objective measurements of lenticular opacity, intraocular pressure, and bone mineral density have failed to reveal significant changes between LABA monotherapy and ICS/LABA combination therapy. ${ }^{49}$ A subset of patients from the KRONOS study of triple therapy were followed for 52 weeks; changes in bone mineral density and ophthalmologic assessments were small and noninferior to the regimen not containing $\mathrm{ICS} .^{52}$

\section{Conclusions}

Formoterol is a highly selective and potent $\beta_{2}$-agonist that has a rapid onset of bronchodilation and a prolonged duration of effect. When administered as monotherapy or in combination with other agents, formoterol effectively improves lung function and reduces the risk of exacerbations and symptoms of COPD. Clinical studies of formoterol provided consistent results across broad patient populations with varying disease severity and characteristics. Different formulations and delivery devices of formoterol products are available to provide treatment options for patients with moderate to severe COPD. Formoterol is well tolerated, with a safety profile similar to that of placebo and minimal effects on the cardiovascular system.

\section{Acknowledgments}

Medical writing support was provided by Shane Walton, PhD, CMPP, of MedErgy (Yardley, PA, USA), which was in accordance with Good Publication Practice (GPP3) guidelines and funded by AstraZeneca (Wilmington, DE, USA).

\section{Disclosure}

DPT serves on advisory boards for AstraZeneca, Sunovion, Mylan, and Theravance/Innoviva and as a speaker for AstraZeneca, Boehringer Ingelheim, and Sunovion. The author reports no other conflicts of interest in this work.

\section{References}

1. Global Initiative for Chronic Obstructive Lung Disease (GOLD). Global Strategy for the Diagnosis, Management, and Prevention of Chronic Obstructive Pulmonary Disease (2020 Report). 2020.

2. Anderson GP. Formoterol: pharmacology, molecular basis of agonism, and mechanism of long duration of a highly potent and selective beta 2-adrenoceptor agonist bronchodilator. Life Sci. 1993;52 (26):2145-2160. doi:10.1016/0024-3205(93)90729-M
3. Cazzola M, Page CP, Calzetta L, Matera MG. Pharmacology and therapeutics of bronchodilators. Pharmacol Rev. 2012;64 (3):450-504. doi:10.1124/pr.111.004580

4. Lecaillon JB, Kaiser G, Palmisano M, Morgan J, Della Cioppa G. Pharmacokinetics and tolerability of formoterol in healthy volunteers after a single high dose of Foradil dry powder inhalation via Aerolizer. Eur J Clin Pharmacol. 1999;55(2):131-138. doi:10.1007/s002280050607

5. Nials AT, Ball DI, Butchers PR, et al. Formoterol on airway smooth muscle and human lung mast cells: a comparison with salbutamol and salmeterol. Eur J Pharmacol. 1994;251(2-3):127-135. doi:10.1016/ 0014-2999(94)90392-1

6. Bouyssou T, Casarosa P, Naline E, et al. Pharmacological characterization of olodaterol, a novel inhaled beta2-adrenoceptor agonist exerting a 24-hour-long duration of action in preclinical models. J Pharmacol Exp Ther. 2010;334(1):53-62. doi:10.1124/jpet.110.167007

7. Slack RJ, Barrett VJ, Morrison VS, et al. In vitro pharmacological characterization of vilanterol, a novel long-acting beta2-adrenoceptor agonist with 24-hour duration of action. J Pharmacol Exp Ther. 2013;344(1):218-230. doi:10.1124/jpet.112.198481

8. Benhamou D, Cuvelier A, Muir JF, et al. Rapid onset of bronchodilation in COPD: a placebo-controlled study comparing formoterol (Foradil Aerolizer) with salbutamol (Ventodisk). Respir Med. 2001;95(10):817-821. doi:10.1053/rmed.2001.1161

9. Richter K, Stenglein S, Mucke M, et al. Onset and duration of action of formoterol and tiotropium in patients with moderate to severe COPD. Respiration. 2006;73(4):414-419. doi:10.1159/000091996

10. Bodzenta-Lukaszyk A, Dymek A, McAulay K, Mansikka H. Fluticasone/formoterol combination therapy is as effective as fluticasone/salmeterol in the treatment of asthma, but has a more rapid onset of action: an open-label, randomized study. BMC Pulm Med. 2011;11:28. doi:10.1186/1471-2466-11-28

11. Maltais F, Ferguson GT, Feldman GJ, et al. A randomized, double-blind, double-dummy study of glycopyrrolate/formoterol fumarate metered dose inhaler relative to umeclidinium/vilanterol dry powder inhaler in COPD. Adv Ther. 2019;36(9):2434-2449. doi:10.1007/s12325-019-01015-3

12. Cazzola M, Ora J, Di Paolo A, Puxeddu E, Calzetta L, Rogliani P. Onset of action of budesonide/formoterol Spiromax ${ }^{\circledR}$ compared with budesonide/formoterol Turbuhaler $^{\circledR}$ in patients with COPD. Pulm Pharmacol Ther. 2016;39:48-53. doi:10.1016/j.pupt.2016.06.006

13. Palmqvist M, Persson G, Lazer L, Rosenborg J, Larsson P, Lotvall J. Inhaled dry-powder formoterol and salmeterol in asthmatic patients: onset of action, duration of effect and potency. Eur Respir J. 1997;10 (11):2484-2489. doi:10.1183/09031936.97.10112489

14. Richter K, Janicki S, Jorres RA, Magnussen H. Acute protection against exercise-induced bronchoconstriction by formoterol, salmeterol and terbutaline. Eur Respir J. 2002;19(5):865-871. doi:10.1183/ 09031936.02.00228502

15. Cazzola M, Paggiaro P, Palange P, et al. Onset of action of formoterol versus salmeterol via dry powder inhalers in moderate chronic obstructive pulmonary disease: a randomized, placebo-controlled, double-blind, crossover study. Clin Drug Investig. 2012;32 (3):147-155. doi:10.2165/11630880-000000000-00000

16. Wedzicha JA, Singh D, Vestbo J, et al. Extrafine beclomethasone/formoterol in severe COPD patients with history of exacerbations. Respir Med. 2014;108(8):1153-1162. doi:10.1016/j.rmed.2014.05.013

17. Kew KM, Mavergames C, Walters JA. Long-acting beta2-agonists for chronic obstructive pulmonary disease. Cochrane Database Syst Rev. 2013;(10):CD010177. doi:10.1002/14651858.CD010177.pub2

18. Gross NJ, Donohue JF. Nebulized formoterol: a review of clinical efficacy and safety in COPD. Int $J$ Chron Obstruct Pulmon Dis. 2010;5:223-232. doi:10.2147/COPD.S11006

19. Tashkin DP, Rennard SI, Martin P, et al. Efficacy and safety of budesonide and formoterol in one pressurized metered-dose inhaler in patients with moderate to very severe chronic obstructive pulmonary disease: results of a 6-month randomized clinical trial. Drugs. 2008;68(14):1975-2000. doi:10.2165/00003495-200868140-00004 
20. Rennard SI, Tashkin DP, McElhattan J, et al. Efficacy and tolerability of budesonide/formoterol in one hydrofluoroalkane pressurized metered-dose inhaler in patients with chronic obstructive pulmonary disease: results from a 1-year randomized controlled clinical trial Drugs. 2009;69(5):549-565. doi:10.2165/00003495-200969050-00004

21. Ferguson GT, Tashkin DP, Skärby T, et al. Effect of budesonide/ formoterol pressurized metered-dose inhaler on exacerbations versus formoterol in chronic obstructive pulmonary disease: the 6-month, randomized RISE (Revealing the Impact of Symbicort in reducing Exacerbations in COPD) study. Respir Med. 2017;132:31-41. doi:10.1016/j.rmed.2017.09.002

22. Ferguson GT, Papi A, Anzueto A, et al. Budesonide/formoterol MDI with co-suspension delivery technology in COPD: the TELOS study. Eur Respir J. 2018;52(3):1801334. doi:10.1183/13993003.01334-2018

23. Calverley PM, Kuna P, Monso E, et al. Beclomethasone/formoterol in the management of COPD: a randomised controlled trial. Respir Med. 2010;104(12):1858-1868. doi:10.1016/j.rmed.2010.09.008

24. Tashkin DP, Doherty DE, Kerwin E, et al. Efficacy and safety characteristics of mometasone furoate/formoterol fumarate fixed-dose combination in subjects with moderate to very severe COPD: findings from pooled analysis of two randomized, 52-week placebo-controlled trials. Int $J$ Chron Obstruct Pulmon Dis. 2012;7:73-86. doi:10.2147/COPD.S29444

25. Vogelmeier C, Paggiaro PL, Dorca J, et al. Efficacy and safety of aclidinium/formoterol versus salmeterol/fluticasone: a Phase 3 COPD study. Eur Respir J. 2016;48(4):1030-1039. doi:10.1183/ 13993003.00216-2016

26. Ferguson GT, Rodriguez-Roisin R, Reisner C, Maes A, Siddiqui S, Martin UJ. Pharmacokinetics of glycopyrronium/formoterol fumarate dihydrate delivered via metered dose inhaler using co-suspension delivery technology in patients with moderate-to-very severe COPD. Int J Chron Obstruct Pulmon Dis. 2018;13:945-953. doi:10.2147/COPD.S154988

27. Reisner C, Fabbri LM, Kerwin EM, et al. A randomized, seven-day study to assess the efficacy and safety of a glycopyrrolate/formoterol fumarate fixed-dose combination metered dose inhaler using novel co-suspension delivery technology in patients with moderate-to-very severe chronic obstructive pulmonary disease. Respir Res. 2017;18 (1):8. doi:10.1186/s12931-016-0491-8

28. Tashkin DP, Martinez FJ, Rodriguez-Roisin R, et al. A multicenter, randomized, double-blind dose-ranging study of glycopyrrolate/formoterol fumarate fixed-dose combination metered dose inhaler compared to the monocomponents and open-label tiotropium dry powder inhaler in patients with moderate-to-severe COPD. Respir Med. 2016;120:16-24. doi:10.1016/j.rmed.2016.09.012

29. Reisner C, Pearle J, Kerwin EM, Rose ES, Darken P. Efficacy and safety of four doses of glycopyrrolate/formoterol fumarate delivered via a metered dose inhaler compared with the monocomponents in patients with moderate-to-severe COPD. Int $J$ Chron Obstruct Pulmon Dis. 2018;13:1965-1977. doi:10.2147/COPD.S166455

30. Martinez FJ, Rabe KF, Ferguson GT, et al. Efficacy and safety of glycopyrrolate/formoterol metered dose inhaler formulated using co-suspension delivery technology in patients with COPD. Chest. 2017;151(2):340-357. doi:10.1016/j.chest.2016.11.028

31. Hanania NA, Tashkin DP, Kerwin EM, et al. Long-term safety and efficacy of glycopyrrolate/formoterol metered dose inhaler using novel Co-Suspension ${ }^{\mathrm{TM}}$ Delivery Technology in patients with chronic obstructive pulmonary disease. Respir Med. 2017;126:105-115. doi:10.1016/j.rmed.2017.03.015

32. Lipworth BJ, Collier DJ, Gon Y, et al. Improved lung function and patient-reported outcomes with co-suspension delivery technology glycopyrrolate/formoterol fumarate metered dose inhaler in COPD: a randomized phase III study conducted in Asia, Europe, and the USA. Int $J$ Chron Obstruct Pulmon Dis. 2018;13:2969-2984. doi:10.2147/COPD.S171835
33. Martinez FJ, Rabe KF, Lipworth BJ, et al. Glycopyrrolate/formoterol fumarate metered dose inhaler improves lung function versus monotherapies in GOLD category a patients with COPD: pooled data from the phase III PINNACLE studies. Int J Chron Obstruct Pulmon Dis. 2020;15:99-106. doi:10.2147/COPD.S229794

34. D'Urzo AD, Rennard SI, Kerwin EM, et al. Efficacy and safety of fixed-dose combinations of aclidinium bromide/formoterol fumarate: the 24-week, randomized, placebo-controlled AUGMENT COPD study. Respir Res. 2014;15(1):123. doi:10.1186/s12931014-0123-0

35. Singh D, Jones PW, Bateman ED, et al. Efficacy and safety of aclidinium bromide/formoterol fumarate fixed-dose combinations compared with individual components and placebo in patients with COPD (ACLIFORM-COPD): a multicentre, randomised study. BMC Pulm Med. 2014;14:178. doi:10.1186/1471-2466-14-178

36. Bateman ED, Chapman KR, Singh D, et al. Aclidinium bromide and formoterol fumarate as a fixed-dose combination in COPD: pooled analysis of symptoms and exacerbations from two six-month, multicentre, randomised studies (ACLIFORM and AUGMENT). Respir Res. 2015;16(1):92. doi:10.1186/s12931-015-0250-2

37. Miravitlles M, Chapman KR, Chuecos F, Ribera A, Gil EG. The efficacy of aclidinium/formoterol on lung function and symptoms in patients with COPD categorized by symptom status: a pooled analysis. Int J Chron Obstruct Pulmon Dis. 2016;11:2041-2053. doi:10.2147/COPD.S114566

38. D'Urzo AD, Singh D, Donohue JF, et al. Efficacy of aclidinium/ formoterol $400 / 12 \mu \mathrm{g}$, analyzed by airflow obstruction severity, age, sex, and exacerbation history: pooled analysis of ACLIFORM and AUGMENT. Int J Chron Obstruct Pulmon Dis. 2019;14:479-491. doi:10.2147/COPD.S185502

39. Sethi S, Kerwin E, Watz H, et al. AMPLIFY: a randomized, phase III study evaluating the efficacy and safety of aclidinium/formoterol vs monocomponents and tiotropium in patients with moderate-to-very severe symptomatic COPD. Int $J$ Chron Obstruct Pulmon Dis. 2019;14:667-682. doi:10.2147/COPD.S189138

40. Singh D, Papi A, Corradi M, et al. Single inhaler triple therapy versus inhaled corticosteroid plus long-acting beta2-agonist therapy for chronic obstructive pulmonary disease (TRILOGY): a double-blind, parallel group, randomised controlled trial. Lancet. 2016;388 (10048):963-973. doi:10.1016/S0140-6736(16)31354-X

41. Vestbo J, Papi A, Corradi M, et al. Single inhaler extrafine triple therapy versus long-acting muscarinic antagonist therapy for chronic obstructive pulmonary disease (TRINITY): a double-blind, parallel group, randomised controlled trial. Lancet. 2017;389 (10082):1919-1929. doi:10.1016/S0140-6736(17)30188-5

42. Papi A, Vestbo J, Fabbri L, et al. Extrafine inhaled triple therapy versus dual bronchodilator therapy in chronic obstructive pulmonary disease (TRIBUTE): a double-blind, parallel group, randomised controlled trial. Lancet. 2018;391(10125):1076-1084. doi:10.1016/ S0140-6736(18)30206-X

43. Ferguson GT, Reisner C, Pearle J, DePetrillo P, Maes A, Martin UJ. Cardiovascular safety profile of a fixed-dose combination of glycopyrrolate and formoterol fumarate delivered via metered dose inhaler using co-suspension delivery technology. Pulm Pharmacol Ther. 2018;49:67-74. doi:10.1016/j.pupt.2018.01.007

44. Rabe KF, Martinez FJ, Ferguson GT, et al. A phase III study of triple therapy with budesonide/glycopyrrolate/formoterol fumarate metered dose inhaler 320/18/9.6 $\mu \mathrm{g}$ and 160/18/9.6 $\mu \mathrm{g}$ using co-suspension delivery technology in moderate-to-very severe COPD: the ETHOS study protocol. Respir Med. 2019;158:59-66. doi:10.1016/j. rmed.2019.08.010

45. Rabe KF, Martinez FJ, Ferguson GT, et al. Triple inhaled therapy at two glucocorticoid doses in moderate-to-very-severe COPD. $N$ Engl J Med. 2020;383(1):35-48. doi:10.1056/NEJMoa1916046 
46. Andreas S, Bothner U, Trampisch M, Haensel M, Buhl R, Alter P. Effect of long-acting beta2-agonists olodaterol and formoterol on heart rate and blood pressure in chronic obstructive pulmonary disease patients. Pulm Pharmacol Ther. 2018;52:1-6. doi:10.1016/j. pupt.2018.08.002

47. Mann M, Chowdhury B, Sullivan E, Nicklas R, Anthracite R, Meyer RJ. Serious asthma exacerbations in asthmatics treated with high-dose formoterol. Chest. 2003;124(1):70-74. doi:10.1378/ chest.124.1.70

48. SYMBICORT ${ }^{\circledR} \quad$ (budesonide and formoterol fumarate dihydrate) [package insert]. Dunkerque, France: AstraZeneca Dunkerque Production; December 2017.

49. Tashkin DP, Strange C. Inhaled corticosteroids for chronic obstructive pulmonary disease: what is their role in therapy? Int $J$ Chron Obstruct Pulmon Dis. 2018;13:2587-2601. doi:10.2147/COPD. $\mathrm{S} 172240$

50. Janson C, Larsson K, Lisspers KH, et al. Pneumonia and pneumonia related mortality in patients with COPD treated with fixed combinations of inhaled corticosteroid and long acting beta 2 agonist: observational matched cohort study (PATHOS). BMJ. 2013;346:f3306. doi:10.1136/bmj.f3306

51. Ferguson GT, Rabe KF, Martinez FJ, et al. Triple therapy with budesonide/glycopyrrolate/formoterol fumarate with co-suspension delivery technology versus dual therapies in chronic obstructive pulmonary disease (KRONOS): a double-blind, parallel-group, multicentre, phase 3 randomised controlled trial. Lancet Respir Med. 2018;6(10):747-758. doi:10.1016/S2213-2600(18)30327-8
52. Kerwin EM, Ferguson GT, Mo M, DeAngelis K, Dorinsky P. Bone and ocular safety of budesonide/glycopyrrolate/formoterol fumarate metered dose inhaler in COPD: a 52-week randomized study. Respir Res. 2019;20(1):167. doi:10.1186/s12931-019-1126-7

53. Lotvall J. Pharmacology of bronchodilators used in the treatment of COPD. Respir Med. 2000;94(suppl E):S6-10. doi:10.1016/S09546111(00)90155-0

54. Zafar MA, Droege C, Foertsch M, Panos RJ. Update on ultra-longacting beta agonists in chronic obstructive pulmonary disease. Expert Opin Investig Drugs. 2014;23(12):1687-1701. doi:10.1517/ 13543784.2014.942730

55. FORADIL AEROLIZER ${ }^{\circledR}$ (formoterol fumarate inhalation powder) [package insert]. Basle, Switzerland: Novartis Pharma AG; September 2012.

56. UTIBRON ${ }^{\mathrm{TM}}$ NEOHALER ${ }^{\circledR}$ (indacaterol and glycopyrrolate) [package insert]. Stein, Switzerland: Novartis Pharma Stein AG; October 2015.

57. STIOLTO ${ }^{\circledR}$ RESPIMAT $^{\circledR}$ (tiotropium bromide and olodaterol inhalation spray) [package insert]. Ridgefield, CT: Boehringer Ingelheim Pharmaceuticals; August 2020.

58. SEREVENT DISKUS (salmeterol xinafoate inhalation powder) [package insert]. Research Triangle Park, NC: GlaxoSmithKline; January 2020.

59. BREO ELLIPTA (fluticasone furoate and vilanterol inhalation powder) [package insert]. Research Triangle Park, NC: GlaxoSmithKline; January 2019 .

\section{Publish your work in this journal}

The International Journal of COPD is an international, peer-reviewed journal of therapeutics and pharmacology focusing on concise rapid reporting of clinical studies and reviews in COPD. Special focus is given to the pathophysiological processes underlying the disease, intervention programs, patient focused education, and self management protocols. This journal is indexed on PubMed Central, MedLine and CAS. The manuscript management system is completely online and includes a very quick and fair peer-review system, which is all easy to use. Visit http://www.dovepress.com/testimonials.php to read real quotes from published authors. 